\title{
AETIOLOGY AND OUTCOME OF COMA IN CHILDREN BETWEEN THE AGE GROUP OF 2 MONTHS-12 YEARS
}

\author{
P. Jhansi Rani1, Elizabeth $B^{2}$
}

${ }^{1}$ Assistant Professor, Department of Paediatrics, Guntur Medical College, Guntur. ${ }^{2}$ Associate Professor, Department of Paediatrics, RIMS, Ongole.

\section{ABSTRACT}

\section{BACKGROUND}

The present study is being conducted in Guntur Medical College/GGH, Guntur to identify aetiology and outcome of acute coma which is one of the most common paediatric emergencies that arouses much anxiety and apprehension in both parents and physicians. We have attempted to delineate neurological signs to predict the prognosis in this study.

Aims and Objectives- 1 . To study the aetiology and outcome of coma in children. 2. To determine the clinical sign predictors of outcome.

\section{MATERIALS AND METHODS}

100 consecutive cases of coma between 2 months and 12 years of age were selected for the study. Aetiology of coma is determined on the basis of clinical history, examination, and relevant laboratory investigations by the treating physician. These children we re followed up till they were discharged from the hospital or till death.

\section{RESULTS}

CNS infections contributed to the majority of cases, non-infectious aetiologies like toxic and metabolic group, post status epilepticus and others contributed to the rest. Survival was significantly better in CNS infections group as compared to those with toxic and metabolic causes.

\section{CONCLUSION}

CNS infections constituted the major bulk of childhood coma. Cerebral malaria (28\%), and viral encephalitis (16\%) were in majority in CNS Infection group.

\section{KEYWORDS}

Coma, CNS Infections.

HOW TO CITE THIS ARTICLE: Rani PJ, Elizabeth B. Aetiology and outcome of coma in children between the age group of 2 months-12 years. J. Evolution Med. Dent. Sci. 2017;6(31):2537-2540, DOI: 10.14260/Jemds/2017/549

\section{BACKGROUND}

Acute coma is a common problem in paediatric population accounting for $10-15 \%$ of all hospital admissions and is associated with significant mortality. Coma in childhood is an important paediatric emergency. It can result from a wide range of primary aetiologies. Neurological outcome in comatose children is of concern to parents and physicians. It may range from absence of impairment to severe disability and death. In hospital neurology, the clinical analysis of unresponsive and comatose children becomes a responsibility. There is always urgency about such medical problems- a need to determine the underlying disease process and the direction in which it is evolving and to protect the brain against more serious or irreversible damage. The terms consciousness, confusion, stupor, unconsciousness, and coma have been endowed with so many different meanings that it is almost impossible to avoid

Financial or Other, Competing Interest: None.

Submission 08-03-2017, Peer Review 20-03-2017,

Acceptance 23-03-2017, Published 17-04-2017.

Corresponding Author:

Dr. Elizabeth $B$,

D. No. 4-8-172,

Near Rana buildings,

Opposite ALA Hospital,

Amaravathi Road, Guntur.

E-mail: drelizabethbandrapalli@gmail.com

DOI: $10.14260 /$ jemds $/ 2017 / 549$

\section{(c) $(i) \$$}

ambiguity in their usage. "A coma is a profound state of unconsciousness. Patients are alive but unable to move or respond to their environment. There are several levels of coma and patients may, or may not, progress through them.

The responsiveness of the brain lessens as the coma deepens and when it becomes more profound, normal body reflexes are lost and the patient no longer responds even to pain. The chances of recovery depend on the severity of the underlying cause. It is unclear whether a deeper coma alone necessarily means a slimmer chance of recovery because some people in deep coma recover well while others in a socalled milder coma sometimes fail to improve."

\section{Methodology \\ Source of Data}

The study group comprised of consecutive 100 children with coma, between the age group 2 months and 12 years, who were admitted in PICU of Guntur Government Hospital.

\section{Inclusion Criteria}

Children between 2 months and 12 years of age with coma, admitted in GGH.

\section{Exclusion Criteria}

- Children less than 2 months and more than 12 years of age.

- Children with neurodevelopmental delay. 
- Any other pre-existing neurological illness.

- Children with traumatic causes of coma

- Children who do not give consent for the study.

\section{Study Design}

It was a prospective observational study conducted on children between age group 2 months and 12 years admitted to PICU, GGH. A well-informed written consent was obtained from the parents/guardians of the subjects. After initial stabilisation of the patients all of them were evaluated at admission (i.e., at ' 0 ' hours) by detailed history taking, clinical examination, MGCS grading. Relevant investigations were done for the arrival of proper diagnosis as per the clinical suspicion. Various investigations performed were $\mathrm{CBC}$, urine analysis, RBS, serum electrolytes, serum ammonia, calcium, ABG, CSF analysis, LFT and imaging studies, and fundoscopy, they were managed accordingly. All the patients underwent a serial neurological examination as per the standard protocol i.e., MGCS scoring and brainstem reflexes at 6 hourly interval, from the time of admission.

\section{MATERIALS AND METHODS}

100 consecutive cases of coma between 2 months and 12 years of age were selected for the study. Clinical signs like temperature, pulse, heart rate, blood pressure, coma severity by MGCS Score, respiratory pattern, pupillary reflex, corneal reflex, extraocular movements, motor pattern, and fundal picture were studied. These findings were recorded at admission (' 0 ' Hour) and after '48 th' Hour of hospital stay. Aetiology of coma is determined on the basis of clinical history, examination, and relevant laboratory investigations by the treating physician. These children were followed up till they were discharged from the hospital or death. Discharged patients were asked for followup after 4 weeks. During this period all of them were evaluated by formal neurological examination and for special sensory involvement. The neurological outcomes were categorised into 6 groups (I-VI) based on the severity of neurological involvement. All the patients were followed till the time of death or discharge from the hospital. Aetiology was classified into infectious, toxic-metabolic, post status epilepsy, and miscellaneous. All the discharged children were asked for followup after 4 weeks and they were assessed by formal clinical neurological examination. Screening for visual and auditory deficits were performed by suitable methods if any suspicion of special sensory involvement was noted, and the findings were recorded. The outcome of coma was allocated into 6 categories based on the severity of neurological impairment.

\begin{tabular}{|c|c|}
\hline \multicolumn{2}{|r|}{ Figure-1. : Grades of severity of neurological outcome } \\
\hline Categony & Neurological status \\
\hline I (Intact) & $\begin{array}{l}\text { Normal of no change from premorbid functioning } \\
\text { Seinures, if recorded, } 100 \% \text { controlled }\end{array}$ \\
\hline II (Milild) & $\begin{array}{l}\text { Minimal afrematicn of tone, powee, of reflexes; aolated cranial } \\
\text { nerve palaies, mild (MRC 4) weakness or ataxia. } \\
\text { Seinures, if present, }>75 \% \text { controlled }\end{array}$ \\
\hline III (Mloderate) & $\begin{array}{l}\text { Moderate (MRC 3) weakness or a ataxia, multiple cranial nerve } \\
\text { involvement. } \\
\text { Seizures, if present, }>50 \% \text { controlled. }\end{array}$ \\
\hline IV (Severe) & $\begin{array}{l}\text { Severe weakness ( OMRC 3) or ataxia; tetraparesis. } \\
\text { Uncoatrolled seizures }\end{array}$ \\
\hline $\mathbf{v}$ (Profound) & Penistent vegetative state \\
\hline V1 & Death \\
\hline
\end{tabular}

\section{RESULTS}

A total of 100 cases of acute coma were included in the study. The age group ranged from 2 months to 12 years. Most of the children presented were between the age group of 1-5 years (51\%) followed by $6-10$ years $(34 \%),<1$ year $(09 \%)$ and $11-$ 12 years $(6 \%)$ in the descending order. In total of 100 cases of coma, 55 were male and 45 were female giving male to female ratio of 1.22: 1 .

\section{Common Presenting Symptoms}

\begin{tabular}{|c|c|c|c|}
\hline Sl. No. & Symptoms & No. of Cases & Percentage \\
\hline 1 & Altered sensorium & 100 & 100 \\
\hline 2 & Convulsions & 89 & 89 \\
\hline 3 & Fever & 76 & 76 \\
\hline 4 & Irritability & 67 & 67 \\
\hline 5 & Headache & 66 & 46 \\
\hline 6 & Nausea and vomiting & 49 & 29 \\
\hline 7 & Lethargy & 29 & 16 \\
\hline 8 & Shortness of breath & 16 & 14 \\
\hline 9 & Poor feeding & 14 & 14 \\
\hline 10 & Behavioural & 14 & 14 \\
\hline 11 & Others & 40 & 40 \\
\hline \multicolumn{3}{|c|}{ Table 1 } \\
\hline
\end{tabular}

\begin{tabular}{|c|c|c|c|c|}
\hline & Aetiology & Total & Survived & Died \\
\hline I & CNS Infections & 58 & $47(81 \%)$ & $13(22.4 \%)$ \\
\hline & Cerebral Malaria & 28 & $25(89.28 \%)$ & $03(10.72 \%)$ \\
\hline & Viral Encephalitis & 16 & $08(50 \%)$ & $08(50 \%)$ \\
\hline & TB Meningitis & 08 & $07(87.5 \%)$ & $01(12.5 \%)$ \\
\hline & $\begin{array}{c}\text { Pyogenic } \\
\text { Meningitis }\end{array}$ & 06 & $05(83.3 \%)$ & $01(16.7 \%)$ \\
\hline II & Toxic/metabolic & 21 & $12(57.1 \%)$ & $09(42.9 \%)$ \\
\hline & $\begin{array}{c}\text { Hepatic } \\
\text { encephalopathy }\end{array}$ & 09 & $04(44.4 \%)$ & $05(55.6 \%)$ \\
\hline & $\begin{array}{c}\text { Hypoxic } \\
\text { encephalopathy }\end{array}$ & 01 & $01(100 \%)$ & - \\
\hline & $\begin{array}{c}\text { Diabetic } \\
\text { ketoacidosis }\end{array}$ & 02 & $02(100 \%)$ & - \\
\hline & Poisoning & 04 & $01(25 \%)$ & $03(75 \%)$ \\
\hline & Snake bite & 02 & $02(100 \%)$ & - \\
\hline III & $\begin{array}{c}\text { Inborn error of } \\
\text { Intractabolism }\end{array}$ & 03 & $02(66.7 \%)$ & $01(33.3 \%)$ \\
\hline IV & Status epilepticus & 09 & $06(66.7 \%)$ & $03(33.3 \%)$ \\
\hline V & Others & 07 & $05(71.4 \%)$ & $02(28.6 \%)$ \\
\hline \multicolumn{4}{|c|}{ Table 2 } \\
\hline
\end{tabular}


CNS infections accounted for $58 \%$ of cases. Toxic/metabolic group constituted $21 \%$ of cases. This is followed by post status epilepticus $9 \%$ and IC bleed $5 \%$. Miscellaneous cases constituted $7 \%$ of cases of coma. Outcome: Mortality was highest among IC bleed (60\%). This is followed by toxic/metabolic causes (42.9\%). Mortality due to CNS infections constituted $22.4 \%$ of all deaths. CNS infections had significantly better survival rate as compared to toxic - metabolic and IC bleed cases. This is consistent with the various other studies.

Abnormal Heart Rate (Tachycardia/bradycardia), abnormal blood pressure (hypertension/hypotension) at ' 0 ' Hour and ' $48^{\text {th' }}$ Hour are associated with high mortality. Poor pulse volume at ' 0 ' Hour didn't correlate significantly with final poor outcome, but majority of the children with poor pulse volume at admission died before 48 hours. However, persistence of poor pulse volume at '48th' Hour is significantly associated with bad outcome. This is due to the fact that most of the cases in our study were dengue shock syndrome with encephalitis, which were treated promptly with fluid resuscitation.

MGCS Score at admission ('0' Hour) has got a strong correlation with the outcome. Lower the score higher the mortality, However, score at ' $48^{\text {th' }}$ Hour had relatively less correlation with mortality. This is because the assessment of MGCS score was confounded by various interventions such as anti-epileptic drugs, sedatives, mechanical ventilation and paralysis, etc.

Abnormal brainstem reflexes like abnormal respiratory pattern, abnormal pupillary reaction, abnormal corneal reflex and abnormal doll's eye sign are associated with bad outcome. Abnormal motor pattern at both ' 0 ' Hour and ' $48^{\text {th' }}$ Hour are associated with poor prognosis.

Presence of neck rigidity doesn't show any correlation with poor outcome. However, presence of neck rigidity in children at '48 th' Hour is associated with slightly higher mortality rate. This may be because, unlike adults, neck rigidity is less common in children. In our study, presence or absence of papilloedema at admission ('0' Hour) didn't show any correlation with the outcome. However, presence of papilledema at ' $48^{\text {th' }}$ Hour of admission was associated with bad prognosis. This difference was because most of them presented with acute onset of coma and papilloedema was not established at ' 0 ' Hours, but its persistence beyond ' $48^{\text {th' }}$ Hour of examination showed grave prognosis. The neurological outcome depends mainly on the aetiology of the coma. Most of the cases (50\%) in CNS Infection group improved with intact neurological outcome (Category-I), as compared to other groups like toxic/metabolic group, where the intact recovery was $28.6 \%$, post status epilepsy $11.1 \%$, IC Bleed 20\%.

\section{DISCUSSION}

Childhood coma is a non-specific consequence of a variety of serious pathological states. Coma is one of the most common paediatric medical problems in emergency paediatrics. Paediatric coma has been for long an enigma with only few studies with inconclusive information, especially in Andhra Pradesh.

In our study, aetiology, two sets of clinical signs as prognostic indicators were studied. First set included vital signs, and second set consisted of specific neurological signs that assessed integrity of cerebral hemispheres and brainstem.

During this present hospital based study, 100 consecutive cases were selected for the study after considering inclusion and exclusion criteria. Of them 55 were male and 45 were female, male to female ratio being 1.22:1. These findings are consistent with other Indian studies ${ }^{1}$. However, another study in Canada $^{2}$ had shown a greater mortality among males compared to females. Analyses of age group revealed that majority of cases were between the age group 1 and 5 Years (42\%). There was no correlation between the age group and mortality. Most common presenting symptoms noted were altered sensorium (100\%), convulsions (89\%), and fever $(76 \%)$, followed by irritability $(67 \%)$, headache $(66 \%)$, skin rashes (54\%). It was observed that neuro infections were the commonest causes of coma in children. These findings are consistent with other studies. In our study, we found that cerebral malaria was the commonest aetiology (28\%). The importance of infectious aetiology in children is in sharp contrast to adult hospital based series where degenerative and cerebrovascular accidents predominate. Among the noninfectious causes, toxic and metabolic causes were the commonest, and were also comparable in frequency with other studies. The overall mortality was $30 \%$ and was slightly higher as compared to other hospital based study, ${ }^{3}$ but was on par with other South East Asian studies. 1,4

The outcome of CNS Infections was significantly better than toxic/metabolic group. Among survivors of CNS Infections in our study, most of them (50\%) improved with intact neurological outcome. After evaluation of physical signs, it was found that fever was not associated with higher risk of mortality or poor outcome. On the other hand, hypothermia spelled poor prognosis. Similar findings are also noted in other studies also. ${ }^{1}$ Abnormal heart rate (tachycardia, bradycardia), abnormal blood pressure (hypertension, hypotension) are associated with increased risk of death and poor neurological outcome as compared to normal parameters. These findings were consistent with other studies as well. But another physical parameter, poor pulse volume at ' 0 ' Hour did not have significant correlation with the mortality, which is in contrast to the study in Chandigarh. ${ }^{1}$ This variation may be due to the fact that most of the cases in our study were dengue shock syndrome with encephalitis, and the initial circulatory instability was corrected promptly with fluid resuscitation. Apart from this most of the cases with poor pulse at ' 0 ' hour died before 48 hours. However, persistence of poor pulse volume at ' $48^{\text {th' }}$ Hour spelled grave prognosis. It is believed that prognosis in coma depends on its severity.

\section{CONCLUSION}

1. Acute coma in childhood is an important paediatric emergency.

2. Out of 100 consecutive cases of coma, 55 were male and 45 were female. The mortality among them were 15 and 15 respectively.

3. Mortality rate was maximum among children of age group 1-5 years (35\%).

4. Most common presenting symptoms were altered sensorium, convulsions, fever, irritability, headache and skin rashes in the descending order. 
5. CNS infections constituted the major bulk of childhood coma. Cerebral malaria (28\%) and viral encephalitis (16\%) were in majority in CNS Infection group.

6. In the present study, the mortality rate was $30 \%$. Mortality was highest among children with intracranial bleed and toxic/metabolic causes of coma. The overall outcome of CNS Infections was significantly better than toxic/metabolic group, and among survivors most of them improved with intact neurological outcome (50\%).

7. Abnormal physical signs such as abnormal heart rate, abnormal BP, have significant correlation with poor outcome both at ' 0 ' Hour, and '48'th' Hour of admission. But another physical sign, poor pulse volume showed significant correlation with bad prognosis only at ' $48^{\text {th' }}$ Hour of admission. This was due to the fact that most of the cases in our study were dengue shock syndrome with encephalitis. The initial circulatory instability was managed adequately with fluid resuscitation at ' 0 ' Hours.

8. The group of patients who had MGCS Score between 3-5 at the time of admission (' 0 ' Hour) had maximum mortality (22/30) as compared to those with score 6-8 $(8 / 30)$.

9. Abnormal brainstem reflexes and abnormal motor pattern were significantly associated with bad prognosis.

10. At a time of rising costs of intensive care, some of the parameters such as physical signs, MGCS Score, and brainstem reflexes provide important prognostic information which can aid in taking decisions for the early interventions and better outcome. This also helps in rational allocation of recourses, especially in countries like India.

In the era of improved resuscitation and life supportive systems, one of the commonest problems faced by the paediatricians is the assessment of a patient in comatose state.

\section{REFERENCES}

[1] Singhi PD, Bansal A, Ramesh S, et al. Predictive value of electroencephalography and computed tomography in childhood non-traumatic coma. Indian J Pediatr 2005;72(6):475-9.

[2] Johnston B, Seshia SS. Prediction of outcome in nontraumatic coma in childhood. Acta neurol scand 1984;69(6):417-27.

[3] Ogunmekan AO, Pediatr JT. Non-traumatic coma in childhood: etiology, clinical findings, morbidity prognosis and mortality. U.S national library of medicine 1983;29(4):230-2.

[4] Sofiah A, Hussain IH. Childhood non-traumatic coma in Kuala Lumpur, Malaysia. Ann Trop Paediatr 1997;17(4):327-31. 